\title{
Investigation of Helicobacter pylori infection among symptomatic children in Hangzhou from 2007 to 2014: A retrospective study with 12796 cases
}

\author{
Xiaoli Shu ${ }^{1}$, Mingfang Ping ${ }^{1,2}$, Guofeng Yin ${ }^{1}$, Mizu Jiang ${ }^{\text {Corresp. } 1}$ \\ ${ }^{1}$ Gastrointestinal Laboratory, the Children's Hospital, Zhejiang University School of Medicine, Hangzhou, China \\ 2 Department of pediatrics, Second Affiliated Hospital of Jiaxing University, Jiaxing, China \\ Corresponding Author: Mizu Jiang \\ Email address: jiangmizu@zju.edu.cn
}

Background and Aim. The infection of Helicobacter pylori (H. pylori) is acquired in childhood and the prevalence vary greatly in different countries and regions. The study aimed to investigate the characteristics of $\mathrm{H}$. pylori infection among children with gastrointestinal symptoms in Hangzhou, a representative city of eastern China. Methods. A systematic surveillance of $\mathrm{H}$. pylori infection according to the ${ }^{13} \mathrm{C}$-urea breath test was conducted from January 2007 to December 2014 in the Children's hospital, Zhejiang University School of Medicine. The demographic information and main symptoms of every subject were recorded. Results. A total of 12796 subjects were recruited and $18.6 \%$ children evaluated as $\mathrm{H}$. pylori positive. The annual positive rates decreased from 2007 to 2014 ( $X^{2}=20.461, p<0.01$ ). The positive rates were $14.8 \%, 20.2 \%$ and $25.8 \%$ in $3-6,7-11$ and 12-17 years age group respectively, which increased with age $\left(X^{2}=116.002, p<0.01\right)$. And it was significantly higher in boys than girls ( $X^{2}=15.090, p<0.01$ ). Multivariate logistic regression identified possible risk factors for $\mathrm{H}$. pylori infection. Age, gender, gastrointestinal symptoms and history of $\mathrm{H}$. pylori infected family member were all significantly associated with $\mathrm{H}$. pylori infection (all $p<0.05$ ). Conclusions. H. pylori infection rates in children with gastrointestinal symptoms were lower than most of those reported in mainland China. Further studies are required to determine the prevalence in the general population. Comprehensively understanding of the characteristics and the possible risk factors of $\mathrm{H}$. pylori infection will be helpful to its management strategies in children in China. 
1 Investigation of Helicobacter pylori infection among symptomatic children in Hangzhou

2 from 2007 to 2014: A retrospective study with 12796 cases

3 Xiaoli Shu ${ }^{1}$, Mingfang Ping ${ }^{1,2}$, Guofeng Yin ${ }^{1}$, Mizu Jiang ${ }^{1}$

$4{ }^{1}$ Gastrointestinal Laboratory, the Children's Hospital, Zhejiang University School of Medicine,

5 Hangzhou, China

$6{ }^{2}$ Department of pediatrics, Second Affiliated Hospital of Jiaxing University, Jiaxing, China

7 Corresponding author: Mizu Jiang, E-mail: mizu@zju.edu.cn

8 Abstract

9 Background and Aim. The infection of Helicobacter pylori (H. pylori) is acquired in childhood 10 and the prevalence vary greatly in different countries and regions. The study aimed to investigate 11 the characteristics of H. pylori infection among children with gastrointestinal symptoms in 12 Hangzhou, a representative city of eastern China.

13 Methods. A systematic surveillance of $\mathrm{H}$. pylori infection according to the ${ }^{13} \mathrm{C}$-urea breath test 14 was conducted from January 2007 to December 2014 in the Children's hospital, Zhejiang 15 University School of Medicine. The demographic information and main symptoms of every 16 subject were recorded.

17 Results. A total of 12796 subjects were recruited and $18.6 \%$ children evaluated as H. pylori

18 positive. The annual positive rates decreased from 2007 to 2014 ( $\left.\chi^{2}=20.461, p<0.01\right)$. The 19 positive rates were $14.8 \%, 20.2 \%$ and $25.8 \%$ in $3-6,7-11$ and $12-17$ years age group respectively,

20 which increased with age $\left(\chi^{2}=116.002, \mathrm{p}<0.01\right)$. And it was significantly higher in boys than 
21 girls $\left(\chi^{2}=15.090, \mathrm{p}<0.01\right)$. Multivariate logistic regression identified possible risk factors for

22 H. pylori infection. Age, gender, gastrointestinal symptoms and history of H. pylori infected

23 family member were all significantly associated with $\mathrm{H}$. pylori infection (all $p<0.05)$.

24 Conclusions. H. pylori infection rates in children with gastrointestinal symptoms were lower

25 than most of those reported in mainland China. Further studies are required to determine the

26 prevalence in the general population. Comprehensively understanding of the characteristics and

27 the possible risk factors of $\mathrm{H}$. pylori infection will be helpful to its management strategies in 28 children in China. 


\section{Introduction}

Helicobacter pylori (H. pylori) is a Gram-negative, microaerophilic bacterium which selectively colonizes in the human stomach mucosa. The prevalence of $\mathrm{H}$. pylori infection is about $50 \%$ of the world's population and gastric cancer related to H. pylori infection is the fourth most common cancer and the second leading cause of cancer-related death worldwide (Atherton \& Blaser 2009). In general, the prevalence in less developed or developing countries is higher than that in developed countries (Fock \& Ang 2010). The infection rates are reported varying from $15.5 \%$ to 93.6\% in developed and developing countries, respectively (Eusebi et al. 2014; Mentis et al. 2015; Tonkic et al. 2012).

It is now accepted that H. pylori infection is acquired in childhood (Rowland et al. 2006), and H. pylori generally persists for the life of the host in the absence of antibiotic therapy (Pacifico et al. 2010). The incidence and prevalence rates of childhood infection with H. pylori also vary greatly worldwide. Within developed nations, prevalence rates of $\mathrm{H}$. pylori infection among children have been shown to range from $6.5 \%$ to $65 \%$ (Roma \& Miele 2015; Tonkic et al. 2012). Now in European and North America, the epidemiology of H. pylori infection in children has changed in recent decades with low incidence rates, which resulting in prevalence lower than $10 \%$ in children and adolescents (Kindermann \& Lopes 2009). However, there were few reports in developing counties. There has been a decrease in the H. pylori infection rate in the general Chinese population in recent years but it also remained high in some areas among both children and adults after fifteen years (Ding et al. 2015; Zhang et al. 2009a).

China is regarded as one of the largest developing country inhabited by more than one-fifth of the world's population although there has been rapid growth in economy in the past decade. The very 
51 limited data showed that the prevalence rate of H. pylori infection in Chinese children ranged

52 from $6.8 \%$ in three cities of China to $72.3 \%$ in northwest China with large regional variations

53 (Ding et al. 2015; Zhang et al. 2009b). Hangzhou, the capital city of Zhejiang Province, which

54 had made quick improvements in industrialization and socioeconomic conditions since the 1980s,

55 is a representative city of eastern China. But few studies have assessed the prevalence of $\mathrm{H}$.

56 pylori infection in this area. The lack of these data in our pediatric population has hampered the

57 better understanding of the disease burden in our society and the healthcare planning for

58 resources allocation to tackle H. pylori-associated diseases which are usually encountered in

59 adulthood. The aim of this study was to estimate the prevalence of $\mathrm{H}$. pylori infection among

60 children in Hangzhou, China from 2007 to 2014 and evaluate the characteristics of H. pylori

61 infection in children. 


\section{Methods}

\section{Study population}

64 Subjects aged from three to 18 years old who were referred for the detection of H. pylori 65 infection using ${ }^{13} \mathrm{C}$-urea breath test $\left({ }^{13} \mathrm{C}\right.$-UBT) were recruited at the Children's hospital, Zhejiang 66 University School of Medicine from January 1, 2007 to December 31, 2014. The main symptoms 67 of every subject, besides a history of H. pylori infected family member were recorded, including 68 abdominal pain, anorexia, nausea/vomiting, abdominal distension, hiccup, constipation, halitosis, 69 diarrhea and failure to thrive/weight loss. All children should have been fasting more than 6hrs, 70 and had not used bismuth salts, proton-pump inhibitors (PPIs), or any antibiotics (amoxicillin, 71 tetracycline, metronidazole, clarithromycin, azithromycin, or other) within one month before the ${ }^{13} \mathrm{C}$-UBT (Koletzko et al. 2011). The major exclusion criteria included: age younger than three or older than 18, children with incomplete patient data, patients who previously diagnosed as $\mathrm{H}$. pylori infection and received treatment for H. pylori infection even with drug withdrawal 4 weeks prior to the ${ }^{13} \mathrm{C}-\mathrm{UBT}$.

\section{Detection of H. pylori infection}

H. pylori infection was established by the ${ }^{13} \mathrm{C}$-UBT kit, Helikit (Isodiagnostika Inc., Edmonton,

$\mathrm{AB}$, Canada) according to standard protocols. Briefly, after a minimum fasting period of $6 \mathrm{hrs}$, a baseline exhaled breath sample was obtained using a collection bag. The children then drank $75 \mathrm{ml}$ of a citrus-flavoured liquid preparation $\left(75 \mathrm{mg}\right.$ of ${ }^{13} \mathrm{C}$-labelled urea). Thirty minutes later, another breath exhaled sample was stored in collection bag. Breath samples were stored at room temperature and then analyzed by an isotope selective nondispersive infrared spectrometer, 
84 positive when delta over baseline (DOB) value calculated after thirty minutes was $3.5 \delta \%$ or

85 more (Mauro et al. 2006).

86 Statistics

87 Descriptive statistics such as median and interquartile range of age, percentages were calculated

88 for demographic data and results were analyzed by chi-squaretest. The distribution of H. pylori

89 infection rate by year was analyzed by Linear-by-Linear association. Multivariate logistic

90 regression analysis was used to control for the potential confounding variables associated with $\mathrm{H}$.

91 pylori infection. Results of logistic regression were expressed as odds ratios (OR) with $95 \%$

92 confidence intervals (CI). Statistical analysis was performed using SPSS version 19.0 (SPSS Inc,

93 USA) and $\mathrm{P}$ value was calculated. Two tailed $\mathrm{P}<0.05$ was considered statistically significant.

\section{Ethical considerations}

95 The study was approved by Institutional Review Board and Institutional Ethics Committees of

96 the Children's hospital, Zhejiang University School of Medicine (2016-IRBAL-078). 
97

98

99 100 101 102 103 104 105 106 107 108 109 110 111 compared to the former four-year period 2007-2010 ( $\left.\chi^{2}=25.798, p<0.01\right)$ (Figure 2$)$. The positive rates of H. pylori was $14.8 \%(800 / 5408)$ in 3-6 years age group, $20.2 \%(1179 / 5829)$ in 7 11 years age group, and $25.8 \%(403 / 1559)$ in $12-17$ years age group, which increased with age rates were higher in boys $(19.9 \%, 1366 / 6880)$ than girls $(17.2 \%, 1016 / 5916)$, and the difference

114 was also statistically significant $\left(\chi^{2}=15.090, \mathrm{p}<0.001\right)($ Table 1$)$. 
115 The main gastrointestinal symptoms of children undergoing ${ }^{13} \mathrm{C}$-UBT are abdominal pain, 116 anorexia, nausea/vomiting, abdominal distension, hiccup, constipation, halitosis, diarrhea and 117 failure to thrive/weight loss. There were $80.7 \%$ children $(10330 / 12796)$ with at least one 118 gastrointestinal symptom in the prior months. The positive rate of H. pylori infection in children 119 with these symptoms was $18.9 \%$ (1950/10330), demonstrating no significant difference 120 compared to $19.3 \%(2466 / 12796)$ children without gastrointestinal symptoms $(17.5 \%, 432 / 2466)$

$\left(\chi^{2}=2.426, p=0.119\right)($ Table 1$)$.

There were 1169 children had a history of H. pylori infected family member, and the H. pylori

infection rate was higher than those without a familial history $\left(20.8 \%\right.$ versus $18.4 \%, \quad \chi^{2}$

$124=4.005, \mathrm{p}<0.05)($ Table 1$)$.

125 Possible risk factors associated with H. pylori infection

Table 2 shows the results from the multivariate logistic regression performed to assess risk infection (all $p<0.05)$. Specifically, children in 7-11 years age group and in 12-17 years age group were 1.474 and 2.031 times as likely to be H. pylori infected as children in 3-6 years age group 
135 infection, as it was 1.141 times in children with gastrointestinal symptoms compared to children 136 without them $(95 \% \mathrm{CI}=1.009-1.289, p<0.05)$. 
137

138

139

140

141

142

143

144

145

146

147

148

149

150

151

152

153

154

155

156

157

158

\section{Discussions}

The present study assessed the ${ }^{13} \mathrm{C}$-UBT in the pre-treatment phase to evaluate current $\mathrm{H}$. pylori infection in children with gastrointestinal symptoms. The prevalence was higher than in developed countries but lower than in some developing countries (Tonkic et al. 2012). It was higher than it reported in three cities (Beijing, Guangzhou and Chengdu) of mainland China, Hong Kong and Taiwan among asymptomatic children or school children, but lower than most of mainland China (Table 3). These could be due to cohort selection, detection method and the geographic area difference which may also reflect the personal and environmental hygiene.

Subjects in our study enrolled from patients most of that had gastrointestinal symptoms and were suggested to detect the H. pylori infection, so the incidence rate would be more or less higher than asymptomatic or general population. Currently, there are many diagnostic tools to detect $\mathrm{H}$. pylori infection, with non-invasive methods being considered as the most desirable for use especially in children. The ${ }^{13} \mathrm{C}$-UBT has been reported to have excellent sensitivity and specificity for the noninvasive identification of $\mathrm{H}$. pylori infection in children and it is recommended for situations when endoscopy is not available or necessary (Guarner et al. 2010; Redéen et al. 2011). ${ }^{13} \mathrm{C}$-UBT has superiority over serologic methods by its high reliability and the ability to differentiate present from past infection (Bourke et al. 2005). The geographic distribution of $\mathrm{H}$. pylori infection is correlated with the geographic distribution of gastric cancer. Muping County in Shandong Province, Wuwei County in Gansu Province and Jiangsu Province are all the area with high risk of gastric cancer (Shi et al. 2008; Zhang et al. 2009a; Zhang et al. 2009b). That may be associated with the high prevalence of H. pylori infection in this area.
Although there is apparent variation in the prevalence of $\mathrm{H}$. pylori infection between developing 
159 and developed countries in children, it is reported all around the world that the prevalence was 160 associated with age (Tkachenko et al. 2007; Zhang et al. 2009a). In our study, the prevalence of 161 H. pylori infection was also shown to increase with age. Pre-school age children had a lower 162 significant prevalence than school age and adolescent. The increase in H. pylori prevalence with 163 age is thought to represent the improvements in socioeconomic conditions and sanitary standards 164 through the generations. In Russia, the prevalence of H. pylori infection reduced markedly within 165 a 10-year period (from 1995 to 2005) due to the improvements in standards of living (Tkachenko 166 et al. 2007). With the development of economic growth in China within decades, the 167 environmental and hygienic conditions were dramatically improved, due to which the prevalence 168 of H. pylori infection is decreasing in China (Nagy et al. 2016). In consistent with it, the annual 169 positive rates decreased during eight-year period (from 2007 to 2014) in our study (Figure 1). 170 The age-dependent manner of $\mathrm{H}$. pylori positive rate in children may also reflect the inverse 171 relation to the socioeconomic status, sanitation and living conditions in China (Zhang et al. 172 2009a). The increase of prevalence might be the effect of accumulation because that the 173 acquisition rates were higher than the loss rates (Ozen et al. 2006). With the growing of age, 174 expanding range of activity, collective living and meal in high school lead to the increase of 175 exposure to H. pylori infection and opportunities to cross infection (Zhang \& Li 2012). But it 176 needs to be further investigated.

177 It was reported that the male predominance of H. pylori infection in adults was a global and 178 homogeneous phenomenon, but such predominance was not apparent in children (de Martel \& 179 Parsonnet 2006; Tkachenko et al. 2007). But our data showed a higher prevalence in boys than 180 girls and in different years age group (Table 2). It is consistent with the study in Brazil that male 
181 gender was one of the risk factors for the acquisition and maintenance of the H. pylori infection 182 (Queiroz et al. 2012). The prevalence of H. pylori infection in a community is related to three 183 factors: the incidence rate of infection, the rate of infection loss (either spontaneous eradication or 184 curative treatment) and the relative survival of those with and without infection. Differential 185 incidence, differential antibiotic exposure or differential protective immunity between genders, 186 which lead to greater loss of infection (or seroreversion) in girls or adults women than in men, 187 may explain the different results observed between children and adult studies (de Martel \& 188 Parsonnet 2006). On the other hand,it may be explained that boys are naturally more active and have poor personal hygiene than girls as the prevalence of H. pylori infection is inversely related to sanitation condition. But the role of gender as a risk factor for $\mathrm{H}$. pylori infection is still debated.

Abdominal complaints such as pain, anorexia, nausea/vomiting, or other dyspeptic symptoms are nonspecific and can be caused by different organic disease within and outside the digestive tract.

The European Pediatric Task Force concluded in their guidelines on management of H. pylori infection that, in children, H. pylori infection is not related to gastrointestinal symptoms (Drumm et al. 2000). Studies comparing the prevalence among symptomatic and asymptomatic children show different results on the relationship between gastrointestinal symptoms and the prevalence of H. pylori infection (Daugule et al. 2007; Dore et al. 2012). A meta-analysis reported recently that children with upper abdominal pain or epigastric pain were at two- to three fold higher risk for H. pylori infection than children without these symptoms but it could not been confirmed in 201 children seen in primary care (Spee et al. 2010). According to multivariate logistic regression analysis, our study showed that gastrointestinal symptom and a history of H. pylori infected 
203 family member were also the significant risk factors for H. pylori infection. Similarly, other 204 studies showed that upper GIT symptoms (RAP, anorexia, nausea), family history of peptic 205 disease, and nausea/vomiting were significantly associated with H. pylori infection (Dore et al. 206 2012; Habib et al. 2014). However, there are many other possible risk factors associated with H. 207 pylori infection identified in most of the published studies, including socioeconomic indicators, 208 family income, household crowding, number of children sharing the same room, parents' 209 education and sharing a bed with children (Ertem 2013). Our results were limited because of 210 cohort selection and the lack of data in these matters, and the determinants of H. pylori infection 211 should be investigated by further studies.

212 In conclusion, the strength of our study was that it evaluated a large number of children in a long 213 period in Hangzhou, a representative city of eastern China. The prevalence of H. pylori infection 214 using ${ }^{13} \mathrm{C}$-UBT increased with age in children and boys were apt to be $\mathrm{H}$. pylori positive 215 compared with girls. The founding suggests that primary infection in childhood is usual and the 216 effect of accumulation might be responsible for the increase of prevalence with age. Besides age 217 and male predominance, gastrointestinal symptom and a history of H. pylori infected family member were also the possible risk factors for H. pylori infection. In children with history of $\mathrm{H}$. pylori infected family member, testing for H. pylori may be considered especially when they are symptomatic. These observations could substantially change H. pylori management strategies in children in China. 


\section{Acknowledgements}

223 We sincerely thank the children and their parents for providing the information to take part in this

224 study. We also thank Lejing Yang and Qian Shu for typewriting the data and thank Kewen Jiang,

225 Weifen Zhu and Xi Chen for suggestions on article editing. 


\section{References}

Atherton JC, and Blaser MJ. 2009. Coadaptation of Helicobacter pylori and humans: ancient history, modern implications. J Clin Invest 119:2475-2487. 38605 [pii]

\subsection{2/JCI38605}

Bourke B, Ceponis P, Chiba N, Czinn S, Ferraro R, Fischbach L, Gold B, Hyunh H, Jacobson K, Jones NL, Koletzko S, Lebel S, Moayyedi P, Ridell R, Sherman P, van Zanten S, Beck I, Best L, Boland M, Bursey F, Chaun H, Cooper G, Craig B, Creuzenet C, Critch J, Govender K, Hassall E, Kaplan A, Keelan M, Noad G, Robertson M, Smith L, Stein M, Taylor D, Walters T, Persaud R, Whitaker S, and Woodland R. 2005. Canadian Helicobacter Study Group Consensus Conference: Update on the approach to Helicobacter pylori infection in children and adolescents--an evidence-based evaluation. Can J Gastroenterol 19:399-408.

Daugule I, Rumba I, Alksnis J, and Ejderhamn J. 2007. Helicobacter pylori infection among children with gastrointestinal symptoms: a high prevalence of infection among patients with reflux oesophagitis. Acta Paediatr 96:1047-1049. 10.1111/j.1651-2227.2007.00329.x

de Martel C, and Parsonnet J. 2006. Helicobacter pylori infection and gender: a meta-analysis of population-based prevalence surveys. Dig Dis Sci 51:2292-2301. 10.1007/s10620-006-9210-5

Ding Z, Zhao S, Gong S, Li Z, Mao M, Xu X, and Zhou L. 2015. Prevalence and risk factors of Helicobacter pylori infection in asymptomatic Chinese children: a prospective, cross-sectional, population-based study. Aliment Pharmacol Ther 42:1019-1026. 10.1111/apt.13364

Dore MP, Fanciulli G, Tomasi PA, Realdi G, Delitala G, Graham DY, and Malaty HM. 2012. Gastrointestinal symptoms and Helicobacter pylori infection in school-age children residing in Porto Torres, Sardinia, Italy. Helicobacter 17:369-373. 10.1111/j.1523-5378.2012.00955.x

Drumm B, Koletzko S, and Oderda G. 2000. Helicobacter pylori infection in children: a consensus statement. European Paediatric Task Force on Helicobacter pylori. J Pediatr Gastroenterol Nutr 30:207-213.

Ertem D. 2013. Clinical practice: Helicobacter pylori infection in childhood. Eur J Pediatr 172:1427-1434. 10.1007/s00431-012-1823-4

Eusebi LH, Zagari RM, and Bazzoli F. 2014. Epidemiology of Helicobacter pylori infection. Helicobacter 19 Suppl 1:1-5. 10.1111/hel.12165

Fock KM, and Ang TL. 2010. Epidemiology of Helicobacter pylori infection and gastric cancer in Asia. $J$ Gastroenterol Hepatol 25:479-486. JGH6188 [pii]

10.1111/j.1440-1746.2009.06188.x

Guarner J, Kalach N, Elitsur Y, and Koletzko S. 2010. Helicobacter pylori diagnostic tests in children: review of the literature from 1999 to 2009. Eur J Pediatr 169:15-25. 10.1007/s00431-009-1033-x

Habib HS, Hegazi MA, Murad HA, Amir EM, Halawa TF, and El-Deek BS. 2014. Unique features and risk factors of Helicobacter pylori infection at the main children's intermediate school in Rabigh, Saudi Arabia. Indian J Gastroenterol 33:375-382. 10.1007/s12664-014-0463-1

Kindermann A, and Lopes AI. 2009. Helicobacter pylori infection in pediatrics. Helicobacter 14 Suppl 1:52-57. 10.1111/j.1523-5378.2009.00700.x

Koletzko S, Jones NL, Goodman KJ, Gold B, Rowland M, Cadranel S, Chong S, Colletti RB, Casswall T, Elitsur Y, Guarner J, Kalach N, Madrazo A, Megraud F, and Oderda G. 2011. Evidence-based guidelines from ESPGHAN and NASPGHAN for Helicobacter pylori infection in children. J Pediatr Gastroenterol Nutr 53:230-243. 10.1097/MPG.0b013e3182227e90

Mauro M, Radovic V, Zhou P, Wolfe M, Kamath M, Bercik P, Croitoru K, and Armstrong D. 2006. 13C urea breath 
test for (Helicobacter pylori): determination of the optimal cut-off point in a Canadian community population. Can J Gastroenterol 20:770-774.

Mentis A, Lehours P, and Mégraud F. 2015. Epidemiology and Diagnosis of Helicobacter pylori infection. Helicobacter 20 Suppl 1:1-7. 10.1111/hel.12250

Nagy P, Johansson S, and Molloy-Bland M. 2016. Systematic review of time trends in the prevalence of Helicobacter pylori infection in China and the USA. Gut Pathog 8:8. 10.1186/s13099-016-0091-7

Ozen A, Ertem D, and Pehlivanoglu E. 2006. Natural history and symptomatology of Helicobacter pylori in childhood and factors determining the epidemiology of infection. J Pediatr Gastroenterol Nutr 42:398-404. 10.1097/01.mpg.0000215307.48169.7b

00005176-200604000-00009 [pii]

Pacifico L, Anania C, Osborn JF, Ferraro F, and Chiesa C. 2010. Consequences of Helicobacter pylori infection in children. World J Gastroenterol 16:5181-5194.

Queiroz DM, Carneiro JG, Braga-Neto MB, Fialho AB, Fialho AM, Goncalves MH, Rocha GA, Rocha AM, and Braga LL. 2012. Natural history of Helicobacter pylori infection in childhood: eight-year follow-up cohort study in an urban community in northeast of Brazil. Helicobacter 17:23-29. 10.1111/j.15235378.2011.00894.x

Redéen S, Petersson F, Törnkrantz E, Levander H, Mårdh E, and Borch K. 2011. Reliability of Diagnostic Tests for Helicobacter pylori Infection. Gastroenterol Res Pract 2011:940650. 10.1155/2011/940650

Roma E, and Miele E. 2015. Helicobacter pylori Infection in Pediatrics. Helicobacter 20 Suppl 1:47-53. 10.1111/hel.12257

Rowland M, Daly L, Vaughan M, Higgins A, Bourke B, and Drumm B. 2006. Age-specific incidence of Helicobacter pylori. Gastroenterology 130:65-72; quiz 211. S0016-5085(05)02264-X [pii]

10.1053/j.gastro.2005.11.004

Shi R, Xu S, Zhang H, Ding Y, Sun G, Huang X, Chen X, Li X, Yan Z, and Zhang G. 2008. Prevalence and risk factors for Helicobacter pylori infection in Chinese populations. Helicobacter 13:157-165. 10.1111/j.15235378.2008.00586. $\mathrm{x}$

Spee LA, Madderom MB, Pijpers M, van Leeuwen Y, and Berger MY. 2010. Association between helicobacter pylori and gastrointestinal symptoms in children. Pediatrics 125:e651-669. peds.2010-0941 [pii]

10.1542/peds.2010-0941

Tkachenko MA, Zhannat NZ, Erman LV, Blashenkova EL, Isachenko SV, Isachenko OB, Graham DY, and Malaty HM. 2007. Dramatic changes in the prevalence of Helicobacter pylori infection during childhood: a 10-year follow-up study in Russia. $J$ Pediatr Gastroenterol Nutr 45:428-432. 10.1097/MPG.0b013e318064589f

Tonkic A, Tonkic M, Lehours P, and Mégraud F. 2012. Epidemiology and diagnosis of Helicobacter pylori infection. Helicobacter 17 Suppl 1:1-8. 10.1111/j.1523-5378.2012.00975.x

Zhang DH, Zhou LY, Lin SR, Ding SG, Huang YH, Gu F, Zhang L, Li Y, Cui RL, Meng LM, Yan XE, and Zhang J. 2009a. Recent changes in the prevalence of Helicobacter pylori infection among children and adults in highor low-incidence regions of gastric cancer in China. Chin Med J (Engl) 122:1759-1763.

Zhang LH, Zhou YN, Zhang ZY, Zhang FH, Li GZ, Li Q, Wu ZQ, Ren BL, Zou SJ, and Wang JX. 2009b. [Epidemiological study on status of Helicobacter pylori in children and teenagers in Wuwei city, Gansu province]. Zhonghua Yi Xue Za Zhi 89:2682-2685.

Zhang Y, and Li JX. 2012. [Investigation of current infection with Helicobacter pylori in children with gastrointestinal symptoms]. Zhongguo Dang Dai Er Ke Za Zhi 14:675-677. 1008-8830(2012)09-0675-03 [pii] 


\section{Table 1 (on next page)}

Table 1 Demographic characteristics of the 12796 subjects 
1 Table 1 Demographic characteristics of the 12796 subjects

\begin{tabular}{|c|c|c|c|c|}
\hline & H. pylori- & H. pylori-negative & Total & Pvalue \\
\hline \multicolumn{5}{|c|}{ Age groups (years) } \\
\hline $3-6$ & $800(14.8)$ & $4608(85.2)$ & 5408 & \multirow[t]{3}{*}{$<0.001$} \\
\hline $7-11$ & $1179(20.2)$ & $4650(79.8)$ & 5829 & \\
\hline $12-17$ & $403(25.8)$ & $1156(74.2)$ & 1559 & \\
\hline \multicolumn{5}{|l|}{ Gender } \\
\hline Female & $1016(17.2)$ & $4900(82.8)$ & 5916 & \multirow[t]{2}{*}{$<0.001$} \\
\hline Male & $1366(19.9)$ & $5514(80.1)$ & 6880 & \\
\hline \multicolumn{5}{|c|}{ Gastrointestinal } \\
\hline symptoms & $432(17.5)$ & $2034(82.5)$ & 2466 & \multirow[t]{3}{*}{0.119} \\
\hline No & $1950(18.9)$ & $8380(81.1)$ & 10330 & \\
\hline Yes & & & & \\
\hline \multicolumn{5}{|c|}{ History of H. pylori } \\
\hline \multicolumn{5}{|c|}{ infected family member } \\
\hline No & $2139(18.4)$ & $9488(81.6)$ & 11627 & \multirow[t]{2}{*}{0.045} \\
\hline Yes & $243(20.8)$ & $926(79.2)$ & 1169 & \\
\hline Total & $2382(18.6)$ & $10414(81.4)$ & 12796 & - \\
\hline
\end{tabular}

2 Data expressed as number (\%). 


\section{Table 2 (on next page)}

Table 2 Logistic regression analysis for possible risk factors associated with H. pylori infection 
Table 2 Logistic regression analysis for possible risk factors associated with H. pylori infection

\begin{tabular}{lll}
\hline Variables & \multicolumn{1}{c}{ OR $(95 \% C I)$} & P value \\
\hline Age groups (years) & & \\
$3-6$ & - & \\
$7-11$ & $1.474(1.335-1.627)$ & $<0.001$ \\
$12-17$ & $2.031(1.772-2.328)$ & $<0.001$ \\
Gender & & \\
$\quad$ Female & - & \\
$\quad$ Male & $1.209(1.104-1.323)$ & $<0.001$ \\
Gastrointestinal symptoms & & \\
No & - & \\
Yes & $1.141(1.009-1.289)$ & 0.035 \\
History of H. pylori infected & & \\
family member & & \\
No & - & \\
Yes & $1.289(1.100-1.511)$ & 0.002 \\
\hline
\end{tabular}

Note: OR, odds ratio; CI, confidence interval. 


\section{Table 3(on next page)}

Table 3 Comparison of prevalence of H. pylori infection among children in China 
1 Table 3 Comparison of prevalence of H. pylori infection among children in China

\begin{tabular}{|c|c|c|c|c|c|c|c|}
\hline Authors & Recruitment & Area & Year & Age (year) & Method & No. & $\begin{array}{c}\text { Prevalence } \\
(\%)\end{array}$ \\
\hline
\end{tabular}




\begin{tabular}{|c|c|c|c|c|c|c|c|}
\hline \multirow{8}{*}{$\begin{array}{l}\text { Ding et al.(Ding et } \\
\text { al. 2015) }\end{array}$} & \multirow{8}{*}{$\begin{array}{l}\text { Asymptomatic } \\
\text { children }\end{array}$} & Beijing & \multirow[t]{8}{*}{ 2009-2011 } & Newborn & \multirow[t]{8}{*}{ HpSA } & 330 & 0.6 \\
\hline & & Guangzhou & & $1-12 \mathrm{~m}$ & & 319 & 2.5 \\
\hline & & Chengdu & & $1-3$ & & 289 & 2.1 \\
\hline & & & & $4-6$ & & 624 & 7.2 \\
\hline & & & & $7-9$ & & 528 & 6.1 \\
\hline & & & & $10-12$ & & 308 & 11.0 \\
\hline & & & & $13-15$ & & 685 & 8.0 \\
\hline & & & & $16-18$ & & 408 & 13.5 \\
\hline \multirow{6}{*}{$\begin{array}{l}\text { Tam et al. (Tam et } \\
\text { al. 2008) }\end{array}$} & \multirow{6}{*}{ School children } & \multirow[t]{6}{*}{ Hong Kong } & \multirow[t]{6}{*}{2007} & $6-8$ & \multirow[t]{6}{*}{ UBT } & 300 & 9.3 \\
\hline & & & & $9-10$ & & 301 & 11.0 \\
\hline & & & & $11-12$ & & 472 & 14.8 \\
\hline & & & & $13-14$ & & 779 & 13.0 \\
\hline & & & & $15-16$ & & 289 & 12.5 \\
\hline & & & & $17-19$ & & 339 & 16.5 \\
\hline \multirow{2}{*}{$\begin{array}{l}\text { Lin et al. (Lin et al. } \\
\text { 2007) }\end{array}$} & \multirow[t]{2}{*}{ School children } & \multirow[t]{2}{*}{ Taiwan } & \multirow[t]{2}{*}{2004} & $9-12$ & \multirow[t]{2}{*}{ Serology } & 1625 & 11.0 \\
\hline & & & & $13-15$ & & 325 & 12.3 \\
\hline \multirow{8}{*}{$\begin{array}{l}\text { Zhang et al. (Zhang } \\
\text { et al. 2009a) }\end{array}$} & \multirow[t]{8}{*}{ School children } & Muping, & \multirow[t]{4}{*}{2006} & $8-9$ & \multirow[t]{4}{*}{ HpSA } & 122 & 26.2 \\
\hline & & \multirow[t]{3}{*}{ Shandong } & & $10-11$ & & 125 & 40.0 \\
\hline & & & & $12-13$ & & 142 & 41.6 \\
\hline & & & & $14-15$ & & 131 & 42.0 \\
\hline & & Yanqing, & 2006 & $8-9$ & $\mathrm{HpSA}$ & 130 & 15.4 \\
\hline & & \multirow[t]{3}{*}{ Beijing } & & $10-11$ & & 136 & 27.9 \\
\hline & & & & $12-13$ & & 125 & 29.6 \\
\hline & & & & $14-15$ & & 125 & 29.6 \\
\hline \multirow{3}{*}{$\begin{array}{l}\text { Chen et al. (Chen et } \\
\text { al. 2007) }\end{array}$} & \multirow{3}{*}{$\begin{array}{l}\text { Population-based } \\
\text { cohort }\end{array}$} & Guangzhou & 2003 & $3-5$ & Serology & 180 & 19.4 \\
\hline & & \multirow[t]{2}{*}{ Guangdong } & & $5-10$ & & 105 & 22.9 \\
\hline & & & & $10-20$ & & 185 & 36.8 \\
\hline \multirow{2}{*}{$\begin{array}{l}\text { Cheng et al. (Cheng } \\
\text { et al. 2009) }\end{array}$} & Population-based & Beijing & 2003 & $2-10$ & UBT & 19 & 57.8 \\
\hline & cohort & & & $11-20$ & & 52 & 46.2 \\
\hline Shi et al. (Shi et al. & Population-based & Jiangsu & $2004-2005$ & $<20$ & UBT/ & 48 & 60.4 \\
\hline 2008) & cohort & & & & Serology & & \\
\hline Zhang et al. (Zhang & Population-based & Wuwei, & $2007-2008$ & $3-5$ & HpSA & 99 & 68.7 \\
\hline et al. 2009b) & cohort & Gansu & & $6-9$ & & 240 & 70.4 \\
\hline & & & & $10-14$ & & 440 & 73.0 \\
\hline & & & & $15-18$ & & 159 & 75.5 \\
\hline Zhang et al. (Zhang & Gastrointestinal & Dongguan, & $2010-2011$ & $3-7$ & Histology/ & 119 & 39.5 \\
\hline \& Li 2012) & symptoms & Guangdong & & $8-12$ & RUT/ & 134 & 41.0 \\
\hline & & & & $13-16$ & UBT & 123 & 54.5 \\
\hline $\mathrm{Wu}$ et al. (Wu et al. & Gastrointestinal & Zunyi & $2000-2006$ & $10-20$ & UBT & 2645 & 40.0 \\
\hline 2008) & symptoms & & & & & & \\
\hline Our study & Gastrointestinal & Hangzhou, & $2007-2014$ & $3-6$ & UBT & 5408 & 14.8 \\
\hline & symptoms & Zhejiang & & $7-11$ & & 5829 & 20.2 \\
\hline & & & & $12-17$ & & 1559 & 25.8 \\
\hline
\end{tabular}

2 Note: HpSA, H. pylori stool antigen test; UBT, urea breath test; RUT, rapid urease test; m, months. 
Figure 1

Figure 1 The distribution of H. pylori infection rate by year from 2007 to 2014

The bars represent the number of enrolled subjects each year. H. pylori negative and positive subjects are white and black respectively. The line chart represent the positive rates of $\mathrm{H}$. pylori infection each year.

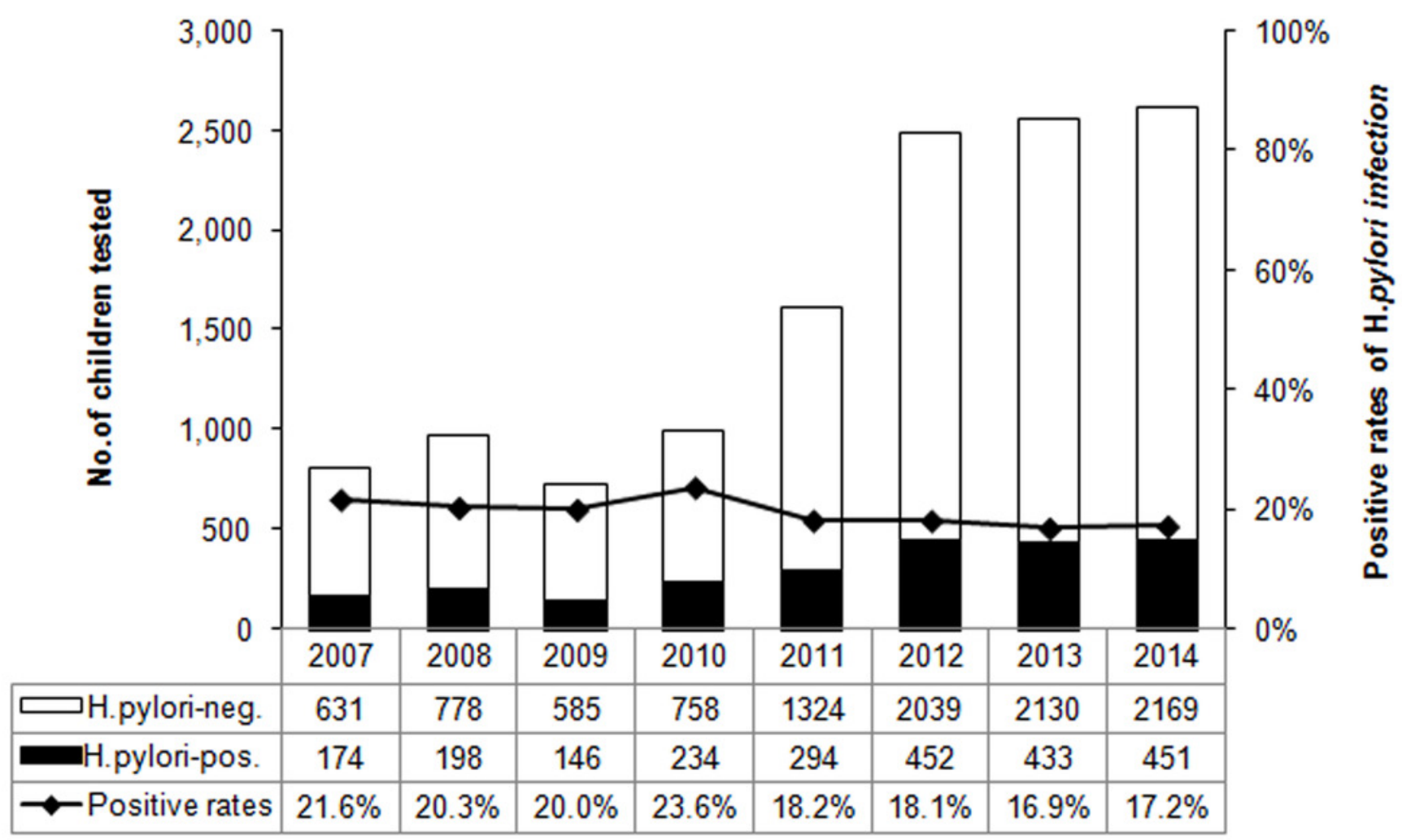


Figure 2

Figure 2 The H. pylori infection rates between two four-year period, 2007-2010 and 2011-2014

The percentages on top of the bars represent the total $\mathrm{H}$. pylori infection rates in four-year periods. ${ }^{* *} p<0.01$.

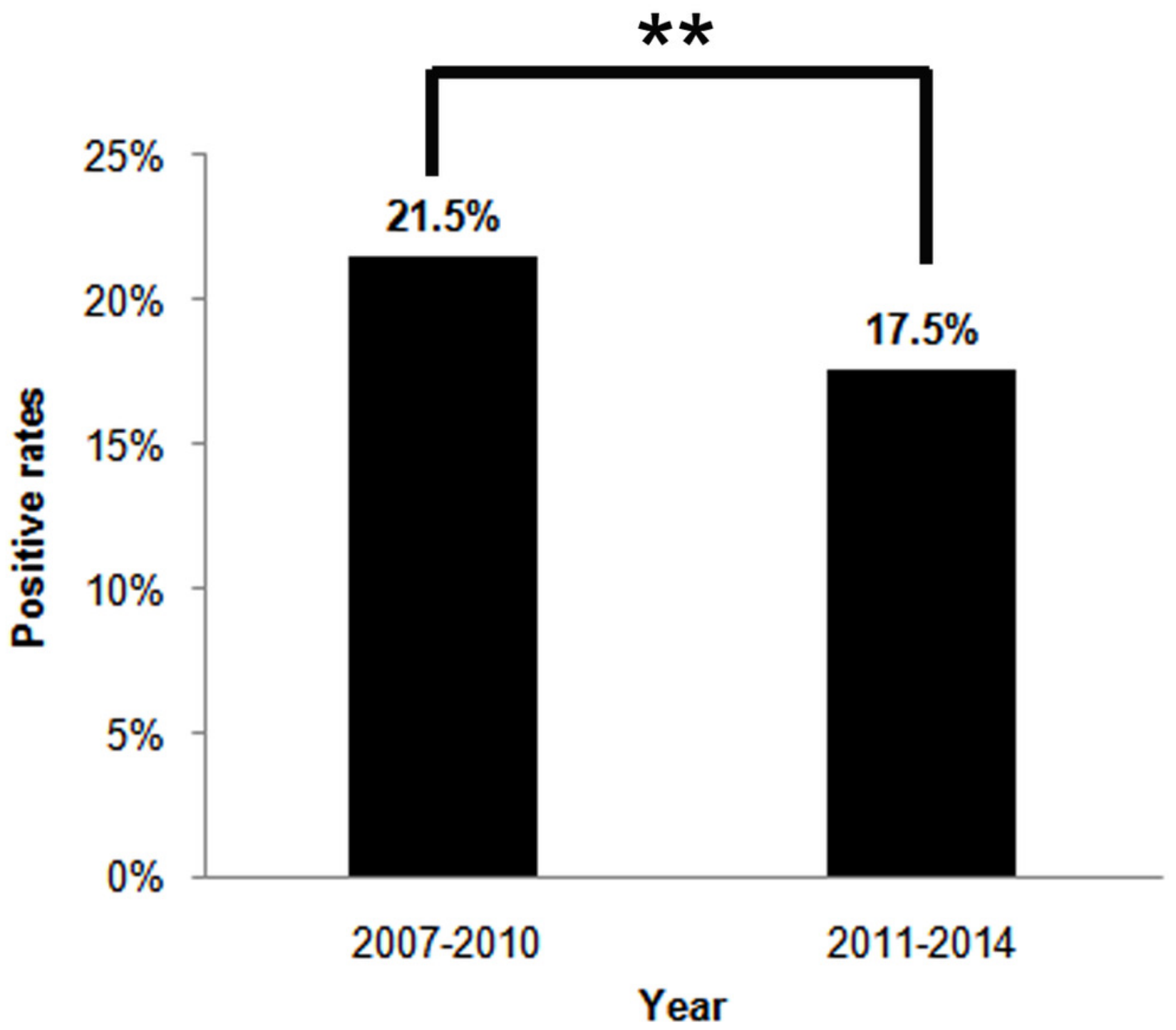

